\title{
Psychological Foundations of Creative Education
}

\author{
Valentin Ageyev \\ "Kainar” University, Almaty, Kazakhstan \\ Email: ageyev@mail.ru
}

Received December 14 $4^{\text {th }}$, 2011; revised January 10 $0^{\text {th }}$, 2012; accepted January 24 $4^{\text {th }}, 2012$

\begin{abstract}
The article suggests considering the translating (consuming) character of contemporary education as its problem. The consuming character of education, exactly, is asserted to be the source of all educational problems. The effort is made to differentiate between the education based on appropriation (consumption of the knowledge and social experience existing in the society) and education based on generation (creativeness, i.e. self-dependent creation of the new knowledge). It is pointed out that under conditions of appropriating (culture-consuming) education it is impossible to raise the ability to create and foresee. This problem can only be solved under conditions of creative (culture-generating) education. This article cites the results of experimental education under the conditions of creative education. The conclusion is drawn on the perspectivity of the educational creative systems elaboration.
\end{abstract}

Keywords: Translating Education; Creative Education; Culture-Consuming Education; Creative Action; Creative Dialogue

\section{Problem}

Economic and social problems, which have fallen on the modern world, testify that today the humankind is unable either to foresee the emergence of non-standard situations, or to foresee the emergence of new problems, or to find the effective solution of new problems in non-standard situations. In our opinion, one of the reasons of such state of things is the catastrophic situation in the educational systems.

Nowadays, the world education is the social institute providing the transmission of the old social experience to the new generations. Such education is based on appropriation (consumption) of the old social experience by the new generations. We got accustomed to this educational system so much that we never think about the fact that under conditions of consumption it is impossible to bring up the ability to creativeness, insight and prediction of further evolution.

In fact, the translating education is the means of conservation of the former achievements, the means of suppression of the further society development. Pedagogical environment has even formed the conviction that children are born with abilities for certain educational subjects or for certain types of activities, as though the children were born with some inherited abilities. Unfortunately, this mistaken opinion is confirmed by the practice of translating education, which long ago became the means of suppression of the personality, the means of submission of the individuum to the socium and conformism formation, the practice of suppression of self-dependence, initiative and creativeness.

As early as in the elementary school, beginning with the first year of studies the environment of translating education disagrees with the creative essence of the man. It has been known since the Renaissance that the sense of human existence, the historical destiny of the man consists in creativeness, generation and self-dependence (Kudryavtzev, 1999; Arsenyev, 2001). In the translating education environment everything is turned upside down. In the appropriation (consumption) environment initiative, self-dependence and creativeness are not simply useless, they become superfluous and disagree with the principles of translating education organization.

In the situation of appropriation the student has to adapt to the assimilated action social pattern. The system of appropriation is the situation of borrowing the individual existence means from the socium with the aim of adaptation to the social life. Therefore, initiative, independent point of view, self-dependence and creativity are the obstacle to the effective organization of the pattern translation and must be expelled from the educational practice. It is usual to speak about creativeness in the situation of appropriated means usage in practice. But one should be aware of the fact that this creativeness is relative, existing in the limits pre-determined by the previous social experience. The appropriated means act as the limiter on further development rather than its source. Development, if it takes place, is the development within the limits restricted by the actual state of the socium. The man can develop, appropriating the social norms and reproducing them effectively, within the limits of actual socium, but he can't fall outside its limits; ha can't create new means. Moreover, it is socially prohibited, because the sense of the social man's existence consists in reproduction of the social norms, i.e. reproduction of the actual socium.

Lots of specialists are trying to find solution to these problems. It is proposed to improve the system of class control (Wragg, 2002). To modernize pedagogics and initial practice (McNamara, 2002). To teach by means of creative decision taking (Clemen \& Gregory, 1995). To use methodologies of imagination development (McKernan, 2008). To organize the effective additional training (Rogers, 2003). The means of improvement of school teaching effectiveness are suggested (Kyriacou, 2009). Foundations of multicultural education have been worked out (Jackson, 2006; Keating, 2007). It is proposed to give consideration to reflexion as the essence of educational practice (Jay, 2003; Russel \& Munby, 2005; Carr, 2005). Some authors find the way out in elaboration of theoretical foundations of Under- 
standing Pedagogy (Lougram, 2003). It is proposed to teach theory and practice at the initial stages of learning (Sharp, Peacock, Johnsley, Simon, Smith, Cross \& Harris, 2009). The attempts to analyze the problems of the teacher which hinder the new approaches in teaching have been going on (Klein, 2006). There has been made the analysis of the class life organization problems which interfere with the school reforms (Kennedy, 2005). Elaboration of modern methods, concepts, technologies and techniques of teaching have been going on (Bhatt, 2002; Gage, 2009; Jarvis, 2006; Westwood, 2008; Petrina, 2007; Newton, 2005; Grant \& Murray, 2002; Clyde \& Delohery, 2005; Dryden \& Vos, 2003). The attempts to work out creative methods of teaching have been made (Woods, 1995; Goodwin, 2004). The search for the methods of teaching effectiveness improvement hasn't been finished (Dunne \& Wragg, 2005). Strategies connected with innovation in teaching and problems solution have been elaborated (Ollington, 2008; Bridgeford, Kitalong \& Self, 2004). Methods of teaching gifted and talented students have been elaborated (Smith, 2005).

But, unfortunately, all these attempts do not transcend the limits of translating education ideology and are, ultimately, based on the principle of appropriation.

In connection with this, we insist that all big and small problems of modern education possess one and the same fundamental reason. This reason is the translating (culture-consuming) character of contemporary education built on the idea of appropriation (consumption) of the old social experience, accumulated in cultural means (ideal and real), by the new generations. Such educational environment suppresses and blocks the genuine human, creative abilities of the students, transforms them into the adaptive ones (Ageyev, 2010).

Such state of things in education results in the slump in learning from the first months of the first years of studies and negative dynamics of motivation till the last year of studies. All this is accompanied by psychic and somatic illnesses which are becoming more and more widespread in the school surrounding.

Encouragement of conformism leads to the fact that the most capable and gifted are "pressed out" onto the periphery of educational space. As a rule, they receive low marks and predominantly pass into the group of the unsuccessful.

On the global basis this leads to the fact that already at school the society loses its most talented pupils and this process goes on at higher educational institutions. It is no mere chance, therefore, that the highest concentration of the gifted are found just in the asocial environment of drug addicts, prostitutes, etc. (Burmenskaya \& Slutzkiy, 1991). This means that the society itself, as a result of organization of the education, which suppresses the free personality, “destroy” its intellectual elite.

\section{The Idea of Problem Solution}

The problem has boiled up to such an extent that the ' facelifting" will be of no use. The problem requires drastic solution. And, exactly, it is necessary to replace the culture-consuming character of education by the culture-generating one (Elkonin, 1994; Slobodchikov \& Issayev, 1995). To reach this aim it is necessary to rethink the essence of the educational situation and rebuild the structure of culture-consuming (adaptive) education into the structure of culture-generative (creative) education. This can only be achieved by means of education based on generation which is understood as the self-dependent crea-

\section{tion of the new knowledge by the students.}

This being said, the creativity is not understood as “... the ability to create the product which possesses novelty and, herewith, corresponds to the context in which it exists. Such a product may be, for instance, the idea, a piece of music, a story or advertisement...” (Lubart, Mouchiroud, Tordgeman \& Zenasni, 2009). Or “... the man's ability to generate unusual ideas, to find original solutions, to deviate from the traditional schemes of thinking...” (Ilyin, 2009). In our opinion, the problem solution is only possible in the case, if the creativity (creative action) is not understood as the ability to create new original products (ideal and real), but as the man's ability to make himself, his abilities, his psychic action the product of generation.

Psychological analysis of the educational situation adaptive structure points to the fact that its foundation consists in the relation Man - concrete historical type of culture. In the process of appropriation of the concrete historical type of culture the child forms the concrete historical type of psyche. This being said, the formation is the process of transformation of the cultural form of social action into the psychic form of individual action. The formation takes place at the expense of reproduction of the cultural form of social action by the psychic form of individual action. When such reproduction is reached, one can speak about the success of appropriation. Just as the cultural forms exist as cultural meanings, so the process of appropriation is the process of transformation of cultural (universal) meanings into individual (singular) meanings. As a result of appropriation the system of cultural meanings turns into the system of individual meanings. The appropriation effectiveness is estimated according to the completeness and adequacy of transformation of cultural meanings into individual meanings. Thereby, on the individual psyche level culture-consumption is the appropriation of cultural meanings by the individuum.

As appropriation takes place according to the mechanism of subjectivation (Hegel), then appropriation has its limits (the thresholds of subjectivation, according to the concept of Batishev, 1997). This means that a student can appropriate only those meanings, which exist within the limits of these thresholds of subjectivation. Under conditions of culture-consuming education the ability towards subjectivation, as well as any other ability, doesn't develop, it remains unchangeable throughout the whole process of teaching. The consequence of this fact is that the development process, supported by the culture-consuming education, is the process of quantitative accumulation of knowledge without any qualitative changes of the abilities, i.e. the development as the process of quantitative accumulation takes place within the threshold of subjectivation and doesn't outstep these limits.

The practice of translating education organization resulted in the widespread point of view on the genetic nature of abilities. It has become fashionable to make an accent on the genius, exclusiveness of isolated students and, consequently, on selection as the decisive factor of the translating education. But such point of view doesn't conform to the creative nature of a man and testifies only to the social hopelessness and unsuitability of educational system, built on the principle of culture-consumption. But if earlier the social development could happen at the expense of action of separate outstanding people without participation of the basic mass of people in social progress, then nowadays temporalization (Dialectical Logics, 1997) is becoming the decisive factor in social development. It anticipates 
the need for participation of each member of the society as the unique and necessary source of social development, rather than its passive participant. We are approaching by leaps and bounds such a time when every man's participation in social development, in the quality of its sovereign source, is becoming vitally important and necessary.

This means that the society can't further orient towards only the intellectual elite upbringing, which is based on the selection of gifted students, ignoring the major part of the humankind. Modern social practice points to the erroneousness of such approach. Our time needs such education which is capable of educating each student as a self-dependent, self-motivated and creative personality. How is it possible?

It will only become possible when the educational situation is founded on the relation historical man-social history of culture, rather than the relation social man-concrete historical type of culture. This being said, social history is understood as the process of emergence and successive change of concrete historical types of culture, and individual history is understood as the process of emergence and successive change of concrete historical types of psyche. Each concrete historical type of culture conforms to the concrete historical type of psyche.

Analysis of the social history of culture development makes it possible to speak about four concrete historical types of culture which take place in the history of human society and which correspond to four concrete historical types of the psyche: spontaneous psyche (magic type of culture), intuitive psyche (mythological culture), reflexive psyche (rational type of culture) and universal psyche (historical type of culture) (Shkuratov, 1997). But, if the first three types of culture (and psyche) represent the shaped stages of evolution in the history, then the fourth one is to be created by the humankind.

The basis for creative education, as distinct from translating (adaptive) education, is becoming the modeling and assimilation of historical logics of culture development (historical logics of meanings development), rather than appropriation of the concrete historical type of culture (concrete historical type of meanings). There are four historical types of meanings: sensory, perceptive, symbolic and universal. The sense of creative education is transformation by the students of the historical logics of culture development into historical logics of their own development, the logics of their own psyche development. Thereat, the evolution of one's own psyche (self-development) is implemented as a result of generation by the students themselves of the new meanings as the means of the new type of psyche designing. As a result of creative education, at the expense of mastering the internal logics of one's own development (selfdevelopment), the student raises the ability to generate new meanings (new type of culture) in problematic situations as means of a new type of psyche designing.

\section{Method of New Possibilities Construction as the Method of the Problem Decision}

In the process of individual development (in ontogenesis) the transition of one type of psyche to its another type is implemented by the students independently in the process of genesis problems solution. The problem of genesis is the contradiction between the new level of the real situation complexity and the available type of meanings as the means of the psychic action. Solving the problematic situation takes place as a result of creation of the new types of meanings, adequate to the level of complexity of a new real situation. The transition between the old and new meanings is implemented as a result of creative action, one of the most important components of which is the creative dialogue (Buber, 1999; Bachtin, 2000; Slobodchikov \& Issayev, 2000; Batishev, 1997). As a result of the creative dialogue there appears the reflexion of meanings development history which transforms into historical logics. Historical logics of meanings origin, applied under the new real conditions, becomes the means of generation of the new meanings-hypotheses. As a result of testing meanings-hypotheses in a new real situation, meanings-hypotheses transform into meanings-knowledge and become the means of creative action for creation of the psyche action of a new type. New meanings act as new possibilities of the psychic action, but the creative action acts as the means of transformation of new possibilities into a new reality of the psychic action.

In the ontogenesis process the students must pass four epochs, each of them representing a certain concrete historical type of psyche. Under the conditions of creative education the psyche is not appropriated from outside, it is designed by the students themselves. Each epoch is subdivided into two stages. The first stage of each epoch creates the possibilities of the new type of psyche action, which emerge as meanings-hypotheses. At the second stage of each epoch the meanings-hypotheses, as the result of testing, turn into meanings-knowledge and act as the means of designing the reality of the new type of the psychic action.

Construction of each concrete historical type of the psychic action is supported with the help of the respective type of methodological system. The type of methodological system is determined by the type of the psychic action, which emerges and forms with its help. Each methodological system also consists of two stages, corresponding to two stages of each ontogenetic epoch (Ageyev, 2004, 2008, 2009, 2010, 2011).

The first stage of each (out of four) methodical systems organizes the independent formulation of the new meaningshypotheses by the students. The main form of such work organization is the constructive discussion (creative dialogue). The aim of the constructive discussion is the self-dependent formulation by the students of the new meanings-hypotheses. This component of educational technology presents the main difficulty for teachers-practitioners. This takes place due to the fact that, being brought up on the ideas of translating education, they try to prompt the solution, fulfill the students' work themselves. But if the constructive discussion isn't organized professionally, the future independent work will be impossible. It is very important for the students to make the subject of analysis and conclusions their own results, obtained as a result of their independent action, not somebody else's formulations.

At the second stage of each methodological system the construction (formation) of a new psychic action takes place with the help of new meanings under conditions of practical tasks solution. As practical tasks become more complicated and demand for their solution the new components of the psychic action structure, the solution of each practical task, next in order of complexity, is supported by the new private methodology as a result of which the students complete the structure of the psychic action with new components. As well as the whole technology of the new possibility construction, each methodical system and each private methodology are built on the same principles of organization of self-dependent creative action, realized in the main forms of its organization. 


\section{Main Principles of Creative Action Organization}

The students are not provided with creative action in the form of the scheme as the pattern (norm) subject to appropriation, it is created by the students themselves on the assumption of the problem situation structure. The aim of creative action is the formation of the psychic action of a new historical type. Its construction starts with new meanings creation. New meanings act as the psychological means of the new psychic action formation. Creative action organization is based on the following main principles.

Principle of self-dependence. Confirms the self-dependence of the students in formulation of aims and tasks put forward, creation of means and methods, as well as the criteria of selfcontrol and self-assessment.

Principle of common solution. New individual possibilities may only be created cooperatively, only when the students treat each other as the aims of their own action, rather than their means. Solution of the genesis problem as the means of transition onto the next level of psychic action evolution can only be created cooperatively, only in the joint creative action.

Principle of common responsibility. This principle presets the necessity of obtaining the common result on the basis of common criteria. The principle of common responsibility presets the necessity of internal organization of the joint action on the basis of common aim, common means and common criteria.

Principle of common criteria. Appears to be fundamental and system-forming. Following this principle gives opportunity to provide the fulfillment of the main task: to make one's own psychic action the aim of joint creative action.

Principle of equal possibilities. In the process of joint construction of the psychic action of the new historical type each student enjoys equal rights in his possibilities with the other students. Creative action may be implemented only as the process of creation of joint possibilities and individualization of the jointly created possibilities on egalitarian basis.

Principle of equal rights. Expresses the sovereignty and right of each student to act in the way he personally sees right. In aggregate with the principles of common solution, common assessment and common criteria composes the system of principles, providing the imprescriptible right of each student for his own position, point of view and viewing the method of the joint creative action organization. Implemented in the form of discussion, persuasion and compromise.

Principle of activity beyond actual possibilities. Expresses determination of the creative action to step out of the actual possibilities of the available type of the psychic action and striving to the continuous overcoming the limits of its own actual possibilities. Appears to be the principle of organization of the genesis problematic situation, the essence of which is the internal contradiction between the actually available and potentially required possibilities.

Principle of personal interest. The cooperative creative action, as the form of cooperative self-development, is the reality, existing at the expense of self-development of each student. The new type of meanings acts, on the one hand, as the product of cooperative efforts and, on the other hand, as the means of individual self-development. As the essence of the creative man is the ability for self-development, then each student is personally interested in the construction of cooperative action and in creation of new meanings as the means of his own self-development.
Principle of personal knowledge. The meaning acquires the personal character as it is the fruit and product of cooperative action to the same degree as the product of the individual action. In depends on every student whether the cooperative action takes place or not, whether culture-generation takes place or not, whether self-development takes place or not.

Principle of observance of minority rights. Expresses the deep democratic character of cooperative creative action which manifests itself in the fact that no action is possible (neither cooperative, nor individual) without regard to each individual opinion, without participation of each student. This principle expresses the right of each student to have his own point of view, and the teacher has to organize the educational process taking into account different (and even alternative) points of view. The only method of adjustment of the polar opinions is persuasion and practice.

Principle of observance of the right for one's own point of view. Proceeds from the principles mentioned above and represents the organization of culture-generating educational process which takes into account the polar points of view and provides the normal educational process in light of the polar points of view.

Principle of pronouncement freedom. Expresses the key significance of a separate student and consolidates the norm of the educational process organization, which doesn't allow the teacher (or the majority) to ignore the opinion of a separate student and binds the teacher to provide such comfortable conditions for each student under which he must have his own point of view. He must be provided with the possibility to express it despite his individual abilities. But each separate opinion must be obligatorily taken into account during the educational process organization.

\section{The Main Forms of the Cooperative Creative Action Organization}

The main principles are realized in the following forms of creative action organization.

Constructive discussion (creative dialogue). The universal form, due to its democratic character and totality, is used at the key stages of the cooperative creative action, which are connected with the establishment of the agreed schemes, criteria and means of its implementation. Exactly, as a result of the discussion, the individual points of view and cooperative strategy of further interrelation must be agreed upon (clearly differentiated). The main principle of the discussion organization is the necessity to find out the true point of view of each student and, on the basis of this knowledge, organize the self-dependent common decision making.

In connection with this, the teacher doesn't have any right to push the students, make hints or prompt the solution. And, therefore, during the discussion organization his work consists in the fact that each student possesses his own point of view, each student can utter and utters his point of view, and each student participates in construction of the solution (rule, criterion, norm) common for the whole educational group. The more thoroughly discussion is organized, the more effectively, on the whole, the educational process will be organized.

Self-dependent formulation of the problem. The effectiveness of the problem solution and self-development practice, on the whole, depends on how adequately the problem is formulated in the problematic situation. The problem formulation 
takes place in the form of discussion, and the most important things is how accurately it will be formulated, how actively each student takes part in the problem formulation, to what degree personal this problem will be perceived by each student, and how accurately the common problem formulation expresses its understanding by each separate student. The problem is the source of creative action, therefore, the success of the problem formulation determines, on the whole, the success of the whole campaign on the further new possibilities construction.

Self-dependent hypotheses formulation. The problem solution is the method of creation of new possibilities (new meanings), i.e. how new possibilities (new meanings) will be created, and how they will be practically applied as the means of creation of the new psychic action for creation of the new reality. The hypothesis is the supposition about the way of turning the available meaning into a new one. New meanings emerge as a result of application of the historical logics to the old meanings under new conditions. Therefore, the formulation of the hypotheses and the aim in the form of discussion determines the success, concrete direction and concrete result of the creative action.

Self-dependent formulation of aims. The new aim as the ideal form of the new result of cooperative creative action is the result of application of the historical logics to the previous aim. Historical logics is preset in the objective form by relation of the old and the new real situations. In order to apply this relation to the aim, it must be subjectivized. Transformation of the objective form of historical logics into its subjective form takes place as a result of designation. Application of the subjectivized historical logics to the initial aims transforms it into the aim of a new historical type.

Self-dependent formulation of tasks. Creative action is the system of interrelated creative deeds. The aim of the creative action is the structure of the new psychic action. The aim of the creative deed is the respective deed in a new structure of the psychic action. The structure of creative action is preset by the structure of transition between the old real and the new real situations. Each intermediate transition in this structure is the specific creative deed, which has its own tasks. The complex of deeds and their succession (structure) are designed by the students themselves. Being aware of the aims to be reached, in order to implement self-development in practice, it is very important to clearly formulate the intermediate tasks, successful solutions of which leads to the aim achievement.

Self-dependent construction of the criteria of self-control and self-assessment. Criteria are the reality of the consciousness, connecting the ideal and real realities of the human action. They are the means of creative action organization, implying integrity, coherence and meaningfulness to the action. The possibility of self-dependent criteria construction is preset by the relation of the old and new real situations. The objective form of the real situation history, subjectivized into historical logics of meanings origination and applied as the means of previous criteria transformation, makes it possible to design new criteria. Self-dependent construction of the new criteria is the way to success of the whole self-development act.

Self-dependent choice of solution models. The spontaneous form of criteria is the model (natural pattern) of the creative action result. For assessment and self-assessment it is necessary to choose the model and establish it as the criterion for all the students of the educational group. All students participate in the discussion, and each of them compulsorily advances his opin- ion and proves it. As a result of the discussion one (or several) model is chosen, which is later used in the quality of the assessment criteria of the fulfilled task correctness for the whole class.

Self-dependent construction of the methods of practical deed. Takes place in the form of a mini-discussion organized by the students themselves in pairs (or other working mini groups). Peculiarity of the mini-discussion and common work in a mini-group is preset by the aim which is formulated by the whole class as a result of the macro-discussion. The task of the mini-discussion is to determine the methods which, according to the opinion of the mini-group participants, correspond to the aim formulated by the class. The result of the mini-discussion is the method of cooperative deed organization which is formulated, coordinated and accepted by all mini-group participants.

Self-dependent construction of practical solution means. This also takes place in the form of a mini-discussion. Each educational mini-group chooses, finds or designs independently the practical solution means coordinated inside the mini-group. Each member of the mini-group has different means, but their choice is made on the presumption that each member bears equal responsibility for the final result of the mini-group and makes his own unique contribution into it.

Mutual control. Cooperative creative action is built as the independent action on the basis of independently formulated criteria. Therefore, the mutual control acts as the system-based factor in cooperative action organization. Necessity and essential significance of mutual control proceed from the common aim and responsibility for the joint result of each student from the educational group. Peculiarity of the cooperative work in the educational group is the necessary coordination in all deeds on the basis of the formulated criteria. Mutual control is the comparison of intermediate results of the deeds for continuous correction of the means of aim achievement. Mutual control is realized in the form of mutual discussion, the result of which is the necessary correction of methods of cooperative deeds.

Self-control. The success of fulfillment of the cooperative action depends directly on the success of each individual contribution. From this point of view, self-control is the most important factor of both individual and cooperative action. Selfcontrol is the relation of the intermediate task and intermediate result of individual action and the correlation of intermediate cooperative action task and intermediate individual action result. Self-control, on the one hand, is the derivative from the mutual control, on the other hand, an individual action is impossible without self-control. Self-control and mutual control emerge simultaneously and present two mutually complementary sides of one cooperative action. Implemented in the individual form, but its necessity, means and result are preset by that cooperative action the component of which is the individual action.

Mutual assessment. Analogical to the mutual control. Difference lies in the fact that the mutual assessment is the relation of the final aims and final results of individual actions with the help of the criteria as psychological means. Has a large significance as the form of emergence and improvement of self-assessment as well as the means of reconstruction and improvement of cooperative action and its effectiveness. Implemented in the form of mini-discussion, first, under direct supervision of the teacher (which results in problematization, inducement to independent finding of solution at the expense of search for the compromise, etc.), later the direct supervision gives place to the more mediated one passing to self-control. 
Self-assessment. Analogical to self-control. Acts as the obligatory component of mutual control, which later becomes differentiated and presents a self-dependent deed. Represents the comparison of the final aim of the individual deed and individual final result, as well as the comparison of the final aim of cooperative deed and the final result of the individual action. Presents itself as the means of self-improvement at the expense of correcting on the ground of the formulated common criteria. Implemented in individual form, first under direct control of the teacher, then acquires more and more autonomous character. Within the limit transforms into the ability to independently design its own individual criteria and act on their basis, irrespective of other people's criteria.

Self-analysis. The subject of self-analysis lies in establishing the relation between the aim of action, the method of implemented action, the process and the obtained result. Coincidence and discrepancy of the aim and result serves as the basis for the conclusions on the character of the implemented action.

Self-analysis is implemented as the component of mutual analysis and presents itself as the most important link in preparation for the next cycle of cooperative (joint) action organization. Implemented in the individual form, first under the direct control of the teacher and another student, then becomes more and more mediated and passes into the autonomous individual regime.

Self-dependent practical work. Presents itself as the most important component of cooperative (joint) action which is, on the one hand, the result of preparatory work in the ideal plan and, on the other hand, the means of testing the ideal plan. Fulfilled by each student separately. The cooperative character of action supposes the constant exchange of information. As well as in the other forms of cooperative action organization, while fulfilling the practical part of the task, no one from the participants of the cooperative deed, by no means, can do somebody else's work. One can persuade, give an advice, appeal, discourage, etc., but by no means do practical work for the other student. This statement emphasizes again the sovereignty of each participant of the joint action and his right of his own sovereign contribution into the joint result. This right is fixed both ideologically and technologically.

Self-dependent construction of the common solution result. Has the fundamental importance because the ability to deliver good results and effectiveness of the mini-group participants is determined by the common result. From this point of view not a single participant of the mini-group can imagine the results of only his own deed as the final one. Likewise, not a single participant can orient towards the quality of his own result, because even the brilliant result of one individual deed in case of the bad result of the other individual deed, will bring about the negative mark of the aggregate result. Therefore, every participant has to orient not only towards the quality of his individual result, but he must orient, in the same degree, towards the result quality of another individual deed. And the result of the joint action will receive the high mark only in the case, when both individual contributions have the high quality. Otherwise, the result of the joint action will be assessed negatively. Construction of the common result is central for organization of the total joint action on the whole, and it takes place in the form of a mini-discussion, the aim of which is coordination of the common result and acceptance of this decision by all participants. Practically, the technology of the common solution construction is based on the rule of prohibition to fulfill the task for another student, in this case to contribute the result of another participant into the construction of common solution. It can only be done by the participant, who has received the result. Another participant can only persuade, appeal, give foundation or contradict the deeds of the first participant, but he doesn't have any right to do some practical work for him, i.e. to include the individual result of another participant into the common construction of the common result.

Self-dependent substantiation of one's own version of the supposed solution result. This form of the cooperative (joint) action organization expresses the sovereign right of each participant to his own point of view. It is fixed technologically in such a way that if the partner doesn't accept the substantiation, there won't be any joint result. Each student has the right to express his point of view, while the result of cooperative action must be cooperative, and the assessment of each participant is the assessment of the cooperative labor. All these conditions preset rather a contradictory position for every participant, who, all the time, has to compare individual and cooperative interests and, all the time, choose and search for compromises between the individual and the cooperative. Takes place in the form of mini- or group discussion, the aim of which is coordination of all opinions and formulations of the single one, cooperative and compromise.

Self-dependent conclusions. Represent the method of establishing the relations between the ideal and real realities of the implemented cooperative (joint) creative action. Conclusions give assessment to both the cooperative action on the whole and peculiarities of its separate components (deeds) fulfillment, as well as effectiveness of the concrete forms of organization. The quality of work of the whole educational group, each participant in particular, as well as the teacher as the organizer of the cooperative creative action of the educational group are assessed simultaneously. As a result of conducted comparisons, correlations and assessments, the decision is made to enter the necessary adjustments and amendments into the character of organization of the next cycle of the creative action.

Thus, as a result of creative education the students assimilate the ability to complement and reconstruct their own psychic action, adjusting it to the new reality. The man, brought up under conditions of creative education, is capable for self-development at the expense of the fact, that he understands the internal logics of the real world development, he is able to predict and anticipate its evolution and, in accordance with the predicted real world development, predict and implement his own development.

In practice, the ability for self-development becomes the ability for solving non-standard problems in non-standard situations. The ability to solve the development problems is the main ability of the creative man.

\section{The Main Results of Experimental Research}

Experimental testing of the technology of the new possibilities construction was implemented very extensively among the students of elementary school age, though separate practice took place in pre-school age institutions, in senior schools as well as in the specialized secondary and higher educational establishments.

The educational practice was organized most systematically within the limits of four experimental projects: boarding school N25, Timiryazev district, Moscow; Experimental pedagogical 
ground “Otrar”, Alma-Ata, Kazakh SSR (1989-1991); Non-government educational establishment "Univerpolice”, Volgodonsk, Rostovskaya oblast (region), Russia (1992-1995); Experimental ground of the Kazakh Academy of pedagogical sciences, High school N4 named after M. Gorky, Taldykurgan, Republic of Kazakhstan (1998-1999).

Separate classes and separate teachers worked for many years under our direct methodological control in different cities and towns of the former Soviet Union, totally about 40 schools, including schools in Latvia, Lithuania, Russia (Ufa, Uchaly, Kazan, Yaroslavl, Voronezh and Voronezhskaya region), Kazakhstan (Alma-Ata, Taldykurgan).

During this period of time more than 100 teachers, more than 1500 students, and more than 20 researchers - developers (teachers and psychologists) took part in the experimental work.

The authenticity of results of the conducted research was supported by the unified logics underlying methodological, theoretical and empiric work-outs at all stages of the realized research. Besides, it was supported by the methodologically founded creative experiment scheme supposing, among other things, the comparison of the results of teaching of the control and experimental groups of students. In our case the participants of experimental groups were the students from different schools, republics and cities of the former USSR and nowadays Kazakhstan, who took part in experimental learning. Experimental groups were represented by students from both city and country schools. The control group included all high school students taught on the basis of culture-consuming (translating) methodology, founded on the basic appropriation processes. Authenticity of the research was supported by positive results received for more than 25 years (from 1986 till nowadays).

\section{Empirical Results}

The main psychological results include, first of all, the positive dynamics of academic motivation supported by the technology of new possibilities construction. The positive dynamics of academic motivation can be defined as the constant increase of students' interest towards learning throughout the whole period of education. The indicators of academic motivation were the wish to attend the lessons, the wish to speak at the board, the wish to participate in a discussion, positive attitude towards the subject, activity in discussion, etc. In order to study the dynamics of academic motivation there were used psychological tests, methods of observation, surveys, etc. Besides, the positive dynamics of academic motivation acted as the criterion for assessment of the practical action of teachers-experimenters, the effectiveness of the system of training and additional training of teachers-experimenters and the effectiveness of the whole methodological service. As compared to the control groups, which included the students educated under conditions of the translating technologies of appropriation, the students of experimental groups always showed the positive dynamics of academic motivation despite age, academic discipline, type of school, locality, etc.

The main psychological results also include positive dynamics of self-dependence of the student's action. The indicators of self-dependence include the following: the ability to possess one's own point of view and defend it, the wish to substantiate one's point of view, the ability to control and assess oneself, the ability to create means and methods of tasks solution, the ability to formulate new aims and tasks, the ability to formulate control criteria and action assessments, the ability to create (choose) the models of tasks solution, etc. The main psychological indicators also include the ability for communication. The indicators of communication ability included the ability to take into account different viewpoints, the ability to change one's viewpoint if somebody proves the necessity of it; the ability to cooperatively formulate the criteria of control and assessment; the ability to cooperatively formulate aims and tasks; the ability to cooperatively create means and methods, the ability to cooperatively synthesize the common result, the ability for mutual help and mutual supportiveness, the ability to listen to another student without interruption, the ability to respect somebody else's viewpoint, etc.

The main objective results include the consistency (integrity) of the acquired knowledge, skills and habits and "theoretical" (total) character.

Objective results of the experimental research show convincingly that application of the new possibilities construction technology in the educational process changes qualitatively the education result and reduces significantly the time for education in comparison to educational technologies based on appropriation.

In the quality of diagnostic situations there were used nonstandard situations, which presupposed the necessity of obtaining the paradoxical results of the practical deed (i.e. the results which, from the first sight, contradict the acquired notion). The application of this method in non-standard situations brings about such results. For example, to give to the students of the second form the initial (acute) angle of $45^{\circ}$ and propose to draw 5 angles, each increasing twice. In this case the second angle will be right, the third-flat angle (straight line), the fourth one and all the rest are circles.

Successful solution of this task is possible only in the case if the ability "to see behind the phenomenon the mode of its origin" is formed, however paradoxical this phenomenon may look. The right solution means that there has been formed the universal (not private) ability to design the ideal reality of the practical deed and implement it in practice, comparing its ideal and real realities. If the ability is formed as the private ability, then the change of the task condition for the non-standard one brings about insuperable difficulties, as the student cannot reconstruct the schemes self-dependently, but is only capable of implementing the acquired schemes of the deed.

The following diagnostic methods were used as complementary: observation, discussion, polling, cross section method, analysis of the action product, etc.

\section{Methodical Results}

The main methodical results of experimental research include the educational technology of new possibilities (new meaning) construction. Educational technology of new possibilities construction is based on the structure of transition between the psychic actions of different historical types. Historical types of psychic actions differ according to the character of their mediatedness. Transitions between the historical types of psychic action are implemented as a result of creative action. Its structure is a psychological foundation of the educational technology of new possibilities construction the aim of which is the production by the students of the new meanings as the means of construction of the new psychic actions. 


\section{Theoretical Results}

They include the psychological concept of self-development. This concept proceeds from understanding the man as the source of evolution of culture, socium and himself. In our opinion, it is possible to overcome the adaptive character of the translating education only in the case if to view development not as the method of "rooting" into the naturally compiled social-cultural situation, but as the means of production of the social-cultural situation itself. In this case the development acquires the character of self-development in the sense that the development as the qualitative self-change becomes possible only as the result of production of the means of development by the developing man himself. Due to the fact that the man is a culturally mediated being, the culture of a new type acts as a new means of self-development. Under the conditions of education self-development is possible at the expense of projecting the educational situation on the basis of the historical principle as the succession of the historical types of real situations replacing one another. The determinant of self-development is the problem of genesis, which is the contradiction between the psychic action of the old historical type and real situation of the new historical type. The cooperative creative action acts as the means of solution of the genetic problem.

\section{Methodological Results}

To the main methodological results of experimental research we refer the method of creative experiment (method of new possibilities construction). This method was worked out for organization of self-development as the qualitative change of the psychic action at the expense of meanings production by students. The result of the new possibilities construction method is the system of principles of the "cross-cutting" educational disciplines construction. The main principle of construction of such disciplines is the historical principle of the practical problems complication. Another principle is the principle of construction of the system of educational disciplines.

This means that the logics of complicacy underlies not only the separate educational disciplines, but the whole system of educational disciplines. The "cross-cutting" educational discipline is the system of increasingly complex practical problems the methods of solution of which are sought for by the students themselves.

Elaboration of the "cross-cutting" educational disciplines requires the historical analysis of the respective system of knowledge as a result of which the internal logics of alternation of the historical types of knowledge in the process of its development is formulated. In working out the "cross-cutting" educational disciplines and the whole "cross-cutting"' system of educational subjects special attention should be paid to the periods of alternation of the subject knowledge historical types, because the periods of subject knowledge types alternation, exactly, are significant for creative education organization. Just as the structure of the real situation (reflected in the structure of knowledge) determines the structure of the psychic action adequate to it, and the structure of transition from one historical type of real situation to another one determines the psychological structure of creative action, so the structure of the real problem situation determines the structure of the psychological problem situation, i.e. fully determines the logics and character of the creative educational process.

\section{Conclusion}

As a result of the long-term massive experimental teaching on the basis of educational technology of the new possibilities construction it was stated, that one of the major practical results is the change of educational motivational dynamics from negative to the positive one and the constant increase of interest to learning. It was shown that not only educational motivation of the students follows the established regularity, but also the motivation of the teacher, who completed the respective system of experimental training, changes in accordance with the revealed regularity.

\section{Inference}

Experimental research showed the following:

- As a result of methodological analysis it was discovered that the attitude towards the social-cultural nature of the man makes it possible to realize only one private model of development-the model of adaptive development (formation). Within the limits of this methodology development will always represent the process of social-cultural adaptation of the man to the actually existing socium.

- There were formulated the basic theses of the new possibilities construction as the methods of new meanings production. The main theses of this method are the following: the man has the historical (universal) nature; socium and culture are the products of interacting individuums; the man is the historical creature producing, due to his creative action, the history of nature, socium, culture and himself; qualitative self-change (self-development) of the man takes place as a result of cooperative creative action representing the method of production by the man of the new meanings; self-development is the way of the man's existence which is the constant transition from one historical type of the psyche action to the other historical type as a result of cooperative creative action.

- The logics of unfolding the creative action structure served as the theoretical basis for elaboration of the new possibilities construction technology. The technology presents four methodological systems, each of them consisting of the concrete methodologies connected by the common logics. The common aim of these methodologies is creation of the respective structural components of the new historical type psychic actions.

- Empirical results prove that the technology of the new possibilities construction is able to solve the major problem of school education-the problem of educational motivation. One of the most important psychological results of experimental research is the positive dynamics of educational motivation throughout the whole period of experimental teaching. This result is especially significant against the background of the negative dynamics of educational motivation, which is the most peculiar feature of the classical system of translating education.

- Practical application of the new possibilities construction technology made it possible to solve the problem of consistency and "theoretical character" of the knowledge acquired by students. We managed to show experimentally that the technology is able to provide successful acquisition by all children of the knowledge which in the real practice of the classical school education is acquired precariously and formally. It especially 
refers to the knowledge the content of which is such notion as "relation".

Such knowledge includes the notion of concentration, the notion of proportion, the notion of the discrete model of substance, consisting of different "kinds" of molecules, the notion of "geometrical shape", etc.

\section{Further Perspectives}

The reason for the longstanding experimental research has become the creation of theoretical and empirical models of culture-generating (creative) education, which could overcome the problems of culture-consuming (adaptive) education. The creative education can give a boost to the substantial reform of educational and upbringing system. Creative education gives opportunity to bring up the new generations not so much with the ability to reproduce the experience of the previous generations as with the ability to produce (create) such an experience. The most important that the system of creative education can do is to bring up people capable of producing the new experience in the problematic situations (new knowledge, new means, new meanings and senses) and make it the social heritage. The results of the conducted experimental research give ground even now to start the large scale practical realization of the new principles of culture-generating education.

\section{REFERENCES}

Ageyev, V. (2004). Technology of construction of the new possibilities. Open School Informational-Methodological Journal, 27, 26-32.

Ageyev, V. (2008). Creative education as a method of "production" of a human being as subject of his own history. XXII World Congress of Philosophy, Seoul, 30 July-5 August 2008.

Ageyev, V. (2009). Creative education as a practical project. 11th European Congress of Psychology, Oslo, 7-10 July 2009.

Ageyev, V. (2010). Creative education as a way of the organization of self-development. Saarbrucken: LAP Lambert Academic Publishing.

Ageyev, V. (2011). Psychological and pedagogical foundations of man's self-development. Almaty.

Arsenyev, A. S. (2001). Philosophical foundations of understanding personality. Moscow: Publishing Centre "Academia".

Bachtin, M. M. (2000). Author and hero: Towards philosophical problems of humanitarian sciences. St. Petersburg: Azbuca.

Batishev, G. S. (1997). Introduction into dialectics of creativity. St. Petersburg: Azbuca.

Bhatt, B. D. (2002). Modern methods of teaching. Concept and techniques. New Delhi: Kanishka Publishers.

Bridgeford, T., Kitalong, K. S., \& Selfe, D. (2004). Innovative approaches to teaching technical communication. Logan, UT: Utah State University Press.

Buber, M. (1999). Two images of faith. Moscow: Publishing House AST.

Burmenskaya, G. V., \& Slutzkiym, V. M. (1991). Gifted children. Moscow: Collection Progress.

Carr, W. (2005). Quality in teaching: Arguments for a reflective profession. London: The Falmer Press.

Clemen, R. T., \& Gregory, R. (1995). Creative decision making: A handbook for active decision makers. Eugene, OR: Decision Science Research Institute.

Clyde, W., \& Delohery, A. (2005). Using technology in teaching. New Haven \& London: Yale University Press.

Dialectical Logics. (1987). Categories of the sphere of essence and integrity. Alma-Ata.

Dryden, G., \& Vos, J. (2003). Revolution in teaching. To teach the world how to learn in a new light. Moscow: PARVINE.

Dunne, R., \& Wragg, T. (2005). Effective teaching. London: Taylor \& Francis e-Library.

Elkonin, B. D. (1994). Introduction in developmental psychology (in the traditions of culture-historical theory of L.S. Vygotsky). Moscow.

Gage, N. L. (2009). A conception of teaching. Stanford, CA: Springer Science + Business Media, LLC.

Goodwin, P. (2004). Literacy through creativity. London: David Fulton Publishers Ltd.

Grant, G., \& Murray, C. E. (2002). Teaching in America. The slow revolution. Cambridge, MA: Harvard University Press.

Ilyin, E. P. (2009). Psychology of creativity and giftness. St. Petersburg.

Jackson, Y. (2006). Encyclopedia of multicultural psychology. Thousand Oaks, CA: Sage Publications, Inc.

Jarvis, P. (2006). The theory and practice of teaching (2nd ed.). London: Taylor \& Francis e-Library.

Jay, J. K. (2003). Quality teaching. Reflection as the heart of practice. Lanham, MD: The Scarecrow Press, Inc.

Keating, A. (2007). Teaching transformation. Transcultural classroom dialogues. New York: Palgrave MacMillan. doi:10.1057/9780230604988

Kennedy, M. (2005). Inside teaching. How classroom life undermines reform. Cambridge, MA: Harvard University Press.

Klein, M. B. (2006). New teaching and teacher issues. New York: Nova Science Publishers, Inc.

Kudryavtzev, V. T. (1999). Psychology of man development. Fundamentals of culture-historical approach. Part I. PC "Expiriment". Riga.

Kyriacou, C. (2009). Effective teaching in schools. Theory and practice (3rd ed.). Cheltenham: Nelson Thornes Ltd.

Loughran, J. (2003). Researching teaching: Methodologies and practices for understanding pedagogy. London: Taylor \& Francis e-Library.

Lubart, T., Mouchiroud, Ch., Torgeman, S. \& Zenasni, F. (2009). Psychology of creativeness. Study Guide/Translation from French. Moscow: Kogito-Centre.

McKernan, J. (2008). Curriculum and imagination. Process theory, pedagogy and action research. London and New York: Taylor \& Francis.

McNamara, D. (2002). Classroom pedagogy and primary practice. London and New York: Routledge.

Newton, D. (2005). Teaching design and technology. Bel Air, CA: Paul Chapman Publishing.

Ollington, G. F. (2008). Teachers and teaching strategies: Innovations and problem solving. New York: Nova Science Publishers, Inc.

Petrina, S. (2007). Advanced teaching methods for the technology classroom. Hershey, PA: Information Science Publishing.

Rogers, B. (2003). Effective supply teaching. Behaviour management, classroom discipline and colleague support. Bel Air, CA: Paul Chapman Publishing.

Russell, T., \& Munby, H. (2005). Teachers and teaching: From classroom to reflection. London: Taylor \& Francis e-Library.

Sharp, J., Peacock, G., Johnsey, R., Simon, S, Smith, R., Cross, A., \& Harris, D. (2009). Primary science. Teaching theory and practice (4th ed.). Exeter: Learning Matters Ltd.

Shkuratov, V. A. (1997). Historical psychology. Moscow: Olman Press.

Slobodchikov, V. I. \& Issayev, E. I. (1995). Psychology of man. Moscow.

Slobodchikov, V. I. \& Issayev, E.I. (2000). Foundations of psychological anthropology. Psychology of man development: Development of subjective reality ontogenesis: Textbook for higher educational institutions. Moscow: School Press.

Smith, C. (2005). Teaching gifted and talented pupils in the primary school. A practical guide. Bel Air, CA: Paul Chapman Publishing.

Westwood, P. (2008). What teachers need to know about teaching methods. Camberwell: ACER Press.

Woods, P. (1995). Creative teachers in primary schools. BuckinghamPhiladelphia: Open University Press.

Wragg, E. C. (2002). Class management in the primary school. London: Taylor \& Francis e-Library. 